\title{
Lung volume reduction surgery as an emergency and life-saving procedure
}

\author{
B. Hansson*, Ph.G. Jorens**, P. van Schil*, W. van Kerckhoven+, \\ F. van den Brande*, E. Eyskens*
}

Lung volume reduction surgery as an emergency and life-saving procedure. B. Hansson, Ph.G. Jorens, P. van Schil, W. van Kerckhoven, F. van den Brande, E. Eyskens. (OERS Journals Ltd 1997.

ABSTRACT: Lung volume reduction surgery (LVRS) is emerging as a promising and unique therapeutic option for rigorously selected patients with severe debilitating emphysema. A 51 yr old man with generalized emphysema developed bilateral pneumothoraces during his first holiday abroad. Due to respiratory insufficiency, intubation and mechanical ventilation were necessary. In total, six chest tubes were inserted but massive air leak persisted and his respiratory condition deteriorated due to bronchopneumonia and sepsis. The patient was transferred to Belgium. As a last resort, bilateral LVRS was performed through a median sternotomy. The most diseased areas of the upper lobes containing the air leak were resected bilaterally and a pleurectomy was associated. Three months after operation, there was a remarkable improvement in spirometric values with an increase in forced expiratory volume in one second of almost $100 \%$. The results were sustained after a follow-up of 18 months.

In this dramatic case, lung volume reduction surgery proved to be effective, and was even a life saving procedure.

Eur Respir J 1997; 10: 2650-2652.
Depts of *Surgery, and **Intensive Care, University Hospital Antwerp, Edegem, Belgium. +Dept of Respiratory Medicine, St-Augustinus Hospital, Antwerp, Belgium

Correspondence: B. Hansson University Hospital Antwerp Division of Thoracic Surgery Wilrijkstraat 10

2650 Edegem

Belgium

Keywords: Emergency

emphysema

lung volume reduction surgery

median sternotomy

respiratory insufficiency

ventilation

Received: April 41997

Accepted after revision August 21997
Lung volume reduction surgery (LVRS) was originally described by BRANTIGAN and MUELLER [1] in 1957, as a surgical treatment for patients with end-stage emphysema. It was reintroduced by COOPER et al. [2] in 1995, who used the term "pneumectomy" to describe resection of poorly ventilated functionless lung. LVRS has become a novel palliative procedure for a subgroup of patients with advanced emphysema [3]. In this case, we performed LVRS in a ventilator dependent patient with chronic obstructive pulmonary disease (COPD), a situation where LVRS has been considered to be contraindicated.

\section{Case report}

A $51 \mathrm{yr}$ old man with severe COPD and a predominant emphysema component due to nicotine abuse had a forced expiratory volume in one second (FEV1) of 0.92 $\mathrm{L}$, which was stable and did not improve despite treatment with bronchodilators and steroids. During his holiday in a southern European country, he experienced fever and dyspnoea, and was therefore admitted to a local hospital. Physical examination revealed severe dyspnoea, a decreased consciousness (with a normal cortical and brain stem function), hypercapnia (arterial carbon dioxide tension $\left.\left(\mathrm{Pa}_{\mathrm{a}, \mathrm{CO}_{2}}\right) 9.57 \mathrm{kPa}(72 \mathrm{mmHg})\right)$, severe obstruction to airflow, expiratory wheezing and fever above $38^{\circ} \mathrm{C}$. A chest radiograph showed a bilateral pneumothorax and thus two chest tubes were inserted to treat the pneumothorax. His condition deteriorated rapidly due to respiratory insufficiency and sepsis, and intubation and mechanical ventilation were necessary. Cardiopulmonary resuscitation (CPR) was initiated because of cardiac arrest. After $1 \mathrm{~min}$, the circulatory state was re-established, and an additional four chest tubes with separated suction systems were inserted (fig. 1). The patient was then transferred to Belgium by a private insurance company.

On arrival, the patient was ventilated by a volumecontrolled ventilator, and enormous airleaks were observed

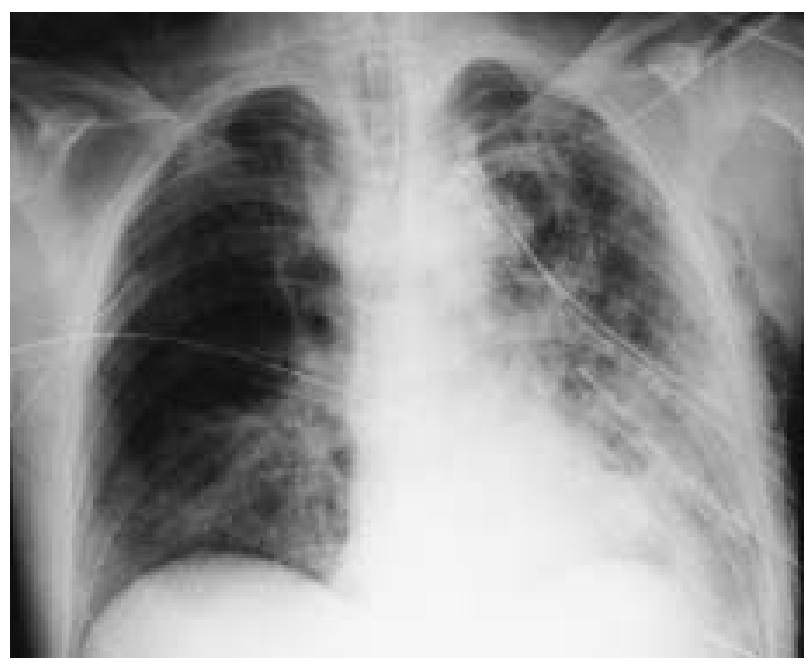

Fig. 1. - A frontal chest radiograph of the patient on arrival with six chest tubes inserted. The patient is intubated and mechanically ventilated. Pulmonary infiltrates are present. 
Table 1. - Spirometric parameters before and after lung volume reduction surgery was performed as an emergency procedure

\begin{tabular}{|c|c|c|c|}
\hline \multirow{2}{*}{$\begin{array}{l}\text { Spirometric } \\
\text { parameters }\end{array}$} & \multirow[t]{2}{*}{ Preoperative } & \multicolumn{2}{|c|}{ Postoperative } \\
\hline & & 3 months & 18 months \\
\hline FEV1 L & 0.92 & $1.86 \quad(62)$ & 1.52 \\
\hline TLC L & 6.57 (111) & 5.34 & 5.79 \\
\hline RV L & $4.06(200)$ & 2.22 (109) & 2.35 (114) \\
\hline VC L & $2.51 \quad(65)$ & 3.12 (98) & $3.44 \quad(91)$ \\
\hline $\begin{array}{l}\text { TL,CO } \\
\mathrm{mmol} \cdot \mathrm{kPa} \cdot \mathrm{min}^{-1}\end{array}$ & (39) & (51) & 4.7 \\
\hline
\end{tabular}

Spirometric parameters with percentage of predicted value in parenthesis. FEV1: forced expiratory volume in one second; TLC: total lung capacity; RV: residual volume; VC: vital capacity; TL,CO: transfer factor of the lungs for carbon monoxide.

a)

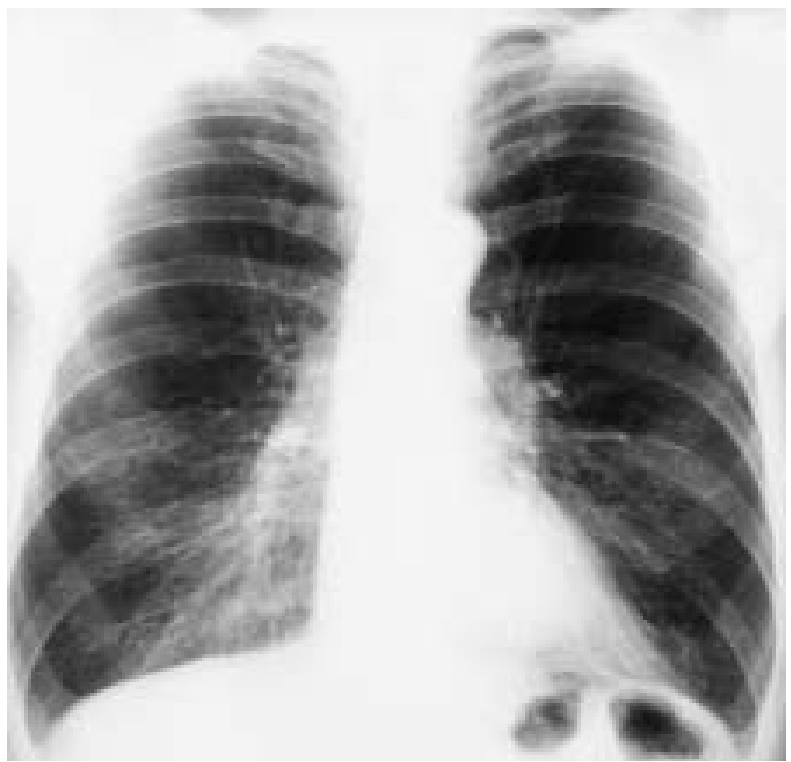

b)

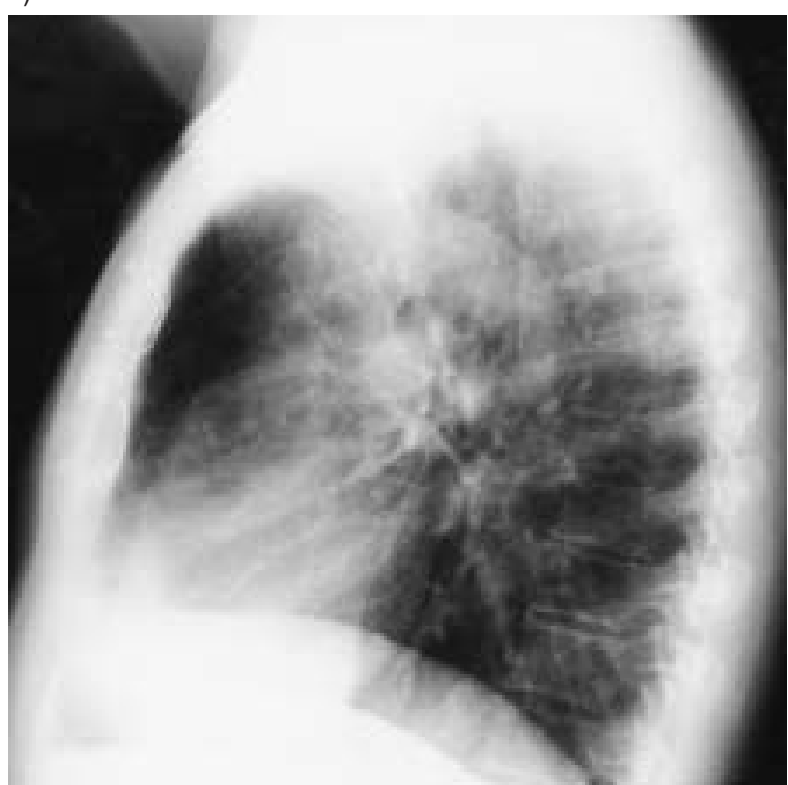

in all suction systems. Inspiratory tidal volume $(V T)$ was $568 \mathrm{~mL}$ and expiratory $V \mathrm{~T} 0 \mathrm{~mL}$. Arterial blood gas analysis with $100 \%$ oxygen were: arterial oxygen pressure $\left(\mathrm{Pa}_{\mathrm{a}} \mathrm{O}_{2}\right) 8.25 \mathrm{kPa}(62 \mathrm{mmHg}) ; \mathrm{Pa}_{\mathrm{a}} \mathrm{CO}_{2} 7.71 \mathrm{kPa}(58$ $\mathrm{mmHg}) ; \mathrm{SO}_{2} 89 \%$; $\mathrm{pH} 7.31 ; \mathrm{HCO} 3-28.5 \mathrm{mmol} \cdot \mathrm{L}^{-1}$. Bronchoscopic evaluation showed a dry necrotic bronchial mucosa in the trachea and both main bronchi. At this moment, the only valuable therapeutic option was LVRS. Through a median sternotomy the most diseased areas of the upper lobes containing the air leak were resected bilaterally, using a linear stapler with strips of bovine pericardium.

A pleurectomy was then performed. On postoperative evaluation only a minimum air leak was present. As a result, four thoracic drains and a mediastinal drain were

c)

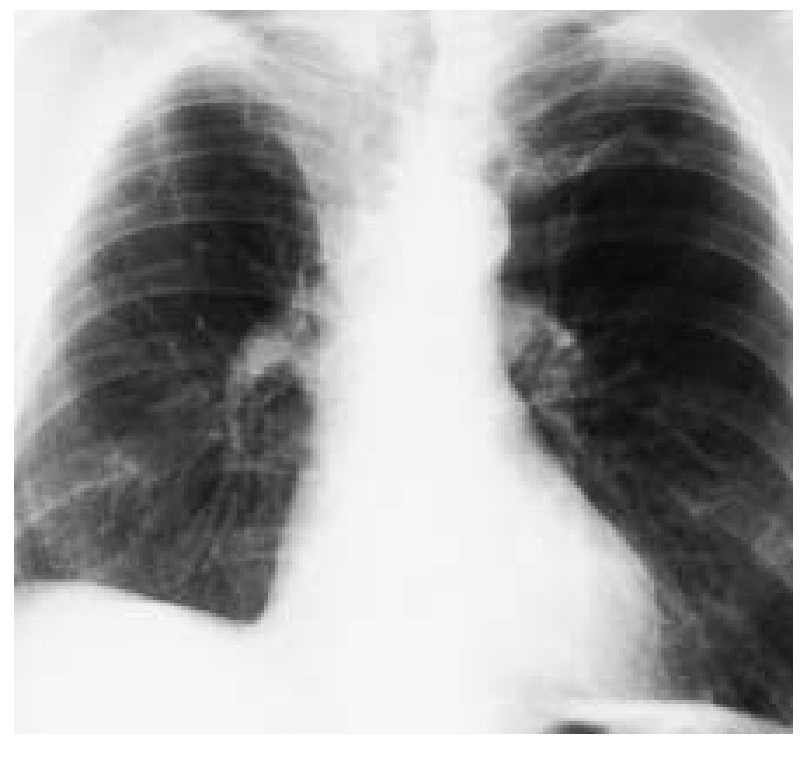

d)

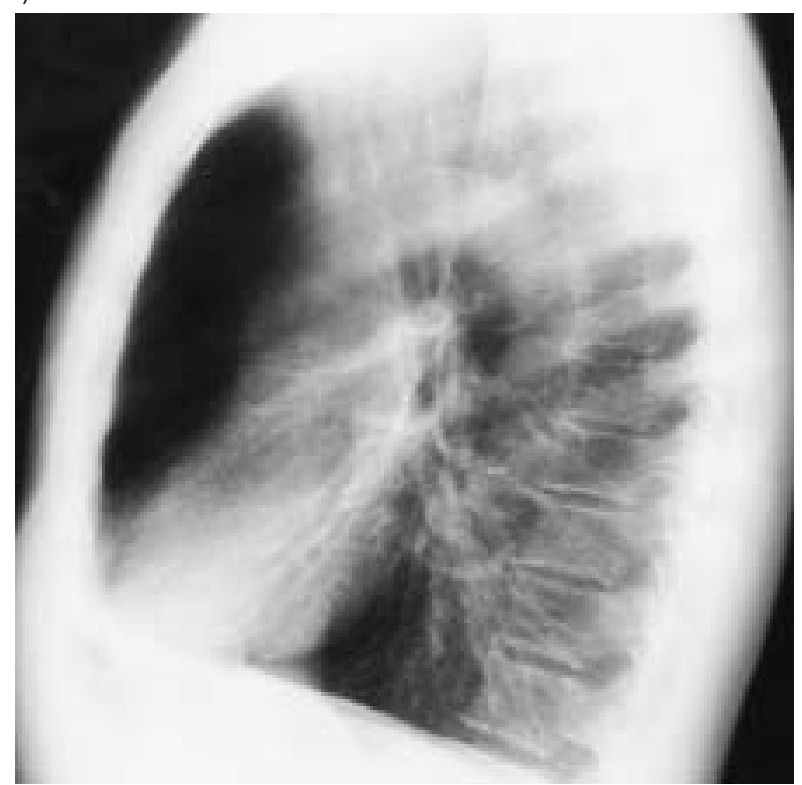

Fig. 2. - Preoperative chest radiographs of: a) frontal; and b) lateral orientations, showing marked hyperinflation of the lungs, with distension of the thorax, and, downward displacement and flattening of the diaphragms. Predominant upper lobe emphysema is present. Postoperative chest radiographs of: c) frontal; and d) lateral orientations, show the return towards a more normal thoracic configuration, with less distension and a higher resting position, and an increased curvature of the diaphragm. 
inserted. The initial postoperative period was complicated by a respiratory infection with Candida albicans (as proven by culture of an aspirate obtained by bronchoscopy). This was treated with intravenous fluconazole. Fourteen days after operation, the patient was extubated, and on the 28th postoperative day he left the hospital and ceased smoking.

Within 3 months, there was a remarkable improvement of spirometric parameters (table 1) and exercise tolerance as assessed by an improved walking distance. Three months after surgery, a significant increase in FEV1 of $100 \%$ was noticed. Total lung capacity (TLC) and residual volume decreased after surgery and almost normal values were observed. The transfer factor of the lung for carbon monoxide increased. Arterial blood gases normalized without hypercapnia or hypoxaemia $\left(\mathrm{Pa}_{\mathrm{a}} \mathrm{CO}_{2}\right.$ $4.92 \mathrm{kPa}(37 \mathrm{mmHg}), \mathrm{Pa}_{2} \mathrm{O}_{2} 12.10 \mathrm{kPa}(91 \mathrm{mmHg}), \mathrm{pH}$ $7.43, \mathrm{HCO}_{3}-24.5 \mathrm{mmol} \cdot \mathrm{L}^{-1}$ while breathing ambient air). Eighteen months postoperatively, spirometric parameters are stable and quality of life is excellent. The chest radiographs before and after LVRS are shown in figure 2.

\section{Discussion}

LVRS is emerging as a promising and unique therapeutic option for rigorously selected patients with severe debilitating emphysema. By resecting hyperinflated nonfunctional areas of the lung, thoracic volume is reduced, chest wall and diaphragmatic mechanics are improved and ventilation to the remaining portions of the lung are improved [4]. The rationale has been that by resecting hyperinflated functionless areas of the lung, the remaining lung will better expand, which will lead to: restoration of elastic recoil resulting in less airflow obstruction and gas trapping; restoration of ventilation-perfusion in previously compressed lung; less distension of the thoracic cage and diaphragm, with improved function of the respiratory muscles; and less dyspnoea [5-7] (fig. 2).

The operative technique can be a unilateral or bilateral procedure using a thoracoscopic or sternotomy approach. McKenNa [10] compared 166 patients treated with unilateral or bilateral thoracoscopic LVRS and concluded that the clinical outcome was much better for the bilateral procedure, with no difference in morbidity and mortality rates. After a bilateral procedure there was more improvement in FEV1, in dyspnoea, and in life expectancy [8-10]. This improvement has proved to be longlasting for at least 2 yrs $[8,9]$.

The bilateral procedure can be performed by a median sternotomy or a bilateral thoracoscopy with approximately equivalent responses [10]. Unilateral procedures may be preferred for hyperinflated patients (TLC $>7.5$ L) with $\mathrm{Pa}_{2} \mathrm{CO}_{2}<5.98 \mathrm{kPa}(45 \mathrm{mmHg})$ and diaphragmatic excursion $>2 \mathrm{~cm}$. These patients have the same improvement in FEV1 whether the procedure is uni- or bilateral [10]. Unilateral operations are also advised for patients with contra-indications for an operation on the opposite side: prior thoracotomy; pleurodesis; extensive pleural diseases; when a large air leak presents while operating on the first side during a planned bilateral pro- cedure; or if underlying skeletal deformities such as pectus excavatum are present $[10,11]$.

NAUnheim et al. [5] published inclusion and exclusion criteria for proper selection, and ventilator dependency is regarded as a contra-indication.

In this patient LVRS was performed as a last resort. An open procedure (median sternotomy) was preferred to a video-assisted thoracoscopic approach, as the patient was ventilated. A spectacular improvement in lung function, oxygenation and quality of life was seen. Even 18 months after the operation, lung function and exercise tolerance are well maintained. Recently CRINER et al. [12] published a report where they operated on three ventilator dependent COPD patients. In all cases there was a successful weaning and an improvement in functional state. They concluded that LVRS in selected ventilated COPD patients may result in improved gas exchange and respiratory mechanics which enables successful weaning and an overall improved functional state.

We conclude that lung volume reduction surgery may be indicated in selected patients with chronic obstructive pulmonary disease, who are ventilator dependent.

\section{References}

1. Brantigan OC, Mueller E. Surgical treatment of emphysema. Am Surg 1957; 23: 789-804.

2. Cooper JD, Trulock EP, Triantafillou AN. Bilateral pneumectomy (volume reduction) for chronic obstructive pulmonary disease. J Thorac Cardiovasc Surg 1995; 109: 106-119.

3. Russi EW, Stammberger U, Weder W. Lung volume reduction surgery for emphysema? Eur Respir J 1997;10: 208-218.

4. Cooper JD, Patterson A. LVRS for severe emphysema. Semin Thorac Cardiovasc Surg 1996; 8: 52-60.

5. Naunheim K, Ferguson M. The current status for lung volume reduction operations for emphysema. Ann Thorac Surg 1996; 62: 601-612.

6. Sciurba FC, Rogers RM, Keenan RJ, et al. Improvement in pulmonary function and elastic recoil after lung volume reduction surgery for diffuse emphysema. $N$ Engl J Med 1996; 334: 1095-1099.

7. Yusen RD, Lefrak SS. Evaluation of patients with emphysema for lung volume reduction surgery. Semin Thorac Cardiovasc Surg 1996; 8: 83-93.

8. Cooper JD, Patterson A, Sundaresan S, et al. Results of 150 consecutive bilateral lung volume reduction procedures in patients with severe emphysema. $J$ Thorac Cardiovasc Surg 1996; 112; 5: 1319-1330.

9. Yusen RD, Trulock EP, Pohl MS, et al. Results of lung volume reduction surgery in patients with emphysema. Semin Thorac Cardiovasc Surg 1996; 8: 99-109.

10. McKenna RJ. Should lung volume reduction surgery for emphysema be unilateral or bilateral? J Thorac Cardiovasc Surg. 1996; 112: 1331-1339.

11. Miller J, Lee RB, Mansour K. Lung volume reduction surgery: lessons learned. Ann Thorac Surg 1996; 61: 1464-1469.

12. Criner J, O'Brien G, Furukawa S, et al. Lung volume reduction surgery in ventilator-dependent COPD patients. Chest 1996; 110; 4: 877-884. 